\title{
Social Justice and Applied Psychology: Practical Ideas for Training the Next Generation of Psychologists
}

Saba Rasheed Ali, Ph.D.

William Ming Liu, Ph.D.

Amina Mahmood, B.A.

JoAnna Arguello, B.A.

University of Iowa

\begin{abstract}
Even though many applied psychology programs embrace a philosophy of social justice, faculty members and trainers are often faced with the practical struggle of implementing a social justice training agenda. This article discusses both the theoretical and practical aspects of implementing a social justice training agenda in applied psychology programs.
\end{abstract}

Keywords: Applied psychology, social justice, psychology training 
Journal for Social Action in Counseling and Psychology

Volume 1, Number 2 Spring 2008

\section{Social Justice and Applied Psychology: Practical Ideas for Training the Next Generation of Psychologists}

In the last decade, there has been a growing interest in advancing social justice within applied psychology programs (Prilleltensky and Nelson, 2002; Vera \& Speight, 2003; Goodman, Liang, Helms, Latta, Sparks, \& Weintraub, 2004). For example, in the discipline of counseling psychology a social justice agenda has been fueled in part by two important movements: (1) a focus on prevention and (2) and the need to expand the definition of multi-cultural competency to include social advocacy and other interventions to reach more diverse groups (Vera \& Speight, 2003). In recent years, individuals within various applied psychology disciplines have developed different models which have provided the theoretical underpinnings of social justice work. These models have offered academic psychologists theoretical constructs that outline the important principles of using a social justice approach to facilitate the empowerment of disenfranchised communities. Many of these models are frameworks on how to teach about social justice in applied work. Yet, it is in the practical application of social justice with which faculty in counseling psychology programs and students often struggle. Implementing social justice in the practical sense is often discussed in the abstract in terms of theoretical models or ideas. While it is important that applied social justice work is based in theoretical frameworks, it is equally important that faculty offer students practical ways to implement social justice initiatives and also provide the space for students and faculty to discuss the very real challenges of this type of work.

Therefore, this paper discusses both the theoretical and practical considerations of incorporating social justice work in an applied psychology training program. First, we will begin by describing existing social justice approaches and theories in which practical examples can be based. We focus mainly on practicum (experiences in which students provide direct clinical services) and classroom based experiences because these are generally two of the main activities in which doctoral students in counseling psychology programs engage. Next, we will provide two practical examples of how a social justice agenda has been integrated into our doctoral program in counseling psychology and the challenges that both the faculty and students faced as a result of trying to implement these social justice experiences.

\section{Social Justice Approaches}

\section{Social Justice in Applied Psychology}

Vera and Speight (2003) argued that for psychologists to be committed to an agenda of multiculturalism, they must also be committed to social justice. Social justice is not only an ideological stance through which clinical, instructional, and research work is filtered, it is also related to behaviors which constitute social justice work. While we recognize that there are many different definitions of social justice and the work that constitutes social justice, the focus on the present article is in line with Goodman et al.'s (2004) application of social justice work to counseling psychologists: "we conceptualize the social justice work of counseling psychologists as scholarship and professional action designed to change societal values, structures, policies, and practices, such that disadvantaged or marginalized groups gain increased access to these tools of self-determination" (p. 795). Additionally, we recognize that this type of work has to be done within a broader framework expanding the roles of counseling psychologists. Vera and Speight write: "issues of social justice cannot be addressed through therapy alone" (Bulhan, 
1995). "A social justice perspective emphasizes societal concerns, including issues of equity, self-determination, interdependence, and social responsibility" (p.254). Vera and Speight further argue that one key way that psychologists can integrate social justice into counseling psychology is to train the next generation of counseling psychology professionals as social justice change agents. They also offer some suggestions for accomplishing this training. They suggest that counseling psychologists in academic settings may want to use service based learning experiences in courses and unique practicum opportunities to help students collaborate with communities and expand their understanding of a psychologist's role in the community. They further argued that these experiences should be tailored to meet community needs and interests.

This suggestion is similar to research on multicultural practicum and its relationship to increasing trainee's multicultural competency (Fouad, 2006; Gross, 2005; Kaslow, Pate, \& Thorn, 2005; Smith, Constantine, Dunn, Dinehar, \& Montoya, 2006). For example, in order to increase multicultural competence among trainees, faculty in counseling psychology programs have created multiculturally focused training programs. These programs extend beyond the ideological (e.g. discussing multiculturalism in the abstract in various courses) and include an actual training component where students work directly with various diverse groups. However, these types of experiences require material, time, and staff resources (Toporek, Liu, \& PopeDavis, 2003). Programs wanting to become social justice focused will also need to use time, money, and resources in order to focus on social justice training. It is important that academic programs also consider how this focus will affect their training and potentially the professional identity as counselors (Liu \& Toporek, 2004) and as psychologists (Toporek \& Liu, 2001).

Before the actual practical training of social justice begins, it is equally important for students to understand the meaning and implications of social justice as a theory as well as implementing theory to practice. Practical models of social justice have been infused within community psychology and social work programs from the outset of these programs and can serve as good models for counseling psychology programs. Additionally, there are also a number of examples of pedagogical practices drawn from the feminist and multicultural pedagogy literature that aid academicians in helping students define the nature of social justice work. Furthermore, counseling psychologists have begun to articulate more practice oriented theoretical frameworks to assist training programs in helping students to understand the principles that underlay a social justice philosophy.

\section{Social Justice Training and Pedagogy}

In the past 30 years, there have been a variety of multicultural and feminist pedagogical approaches that have been used to teach students about diversity, oppression, and social justice (Enns \& Forrest, 2004). These approaches served as important theoretical frameworks for instructors to implement social justice agenda in their own classrooms and emphasize the following: (a) holistic learning based in conscientization and consciousness raising (e.g. coming to consciousness about oppression and using this consciousness to teach and empower others) and using teaching methods that are designed to build connections between personal experience and social issues (b) a reliance on egalitarian methods such as participatory learning, dialogue, and self-reflection and (c) an effort to equalize power inequities in the teacher-student relationship and classroom dynamics (Enns \& Forrest, 2004). 
Community psychology has also been active in a social justice agenda since its inception (Moane, 2003). Recently, two community psychologists, Issaac Prilletensky and his colleague, Geoffery Nelson (2002) outlined a critical psychology approach that focuses on helping students to learn about social issues within the classroom, but also to use class projects to promote citizenship and activism. These authors also discuss the importance of field training, in which students are placed in a variety of settings that enable them to work collaboratively with disenfranchised communities. Like the multicultural-feminist approaches, Prillentensky and Nelson stress the importance of students having a place to process their work in these settings. Faculty need to provide structure and guidance to help students reflect on their experiences, facilitate mentoring and supervision, and discuss the real life difficulties and challenges that students face in trying to be social change agents.

\section{Social Justice Model of Practical Application}

Goodman et al. (2004) identified six recurring themes emerging in the multicultural literature that they used to define the essence of a practical application of social justice to counseling psychology. In particular, this application focuses on using a social justice lens to collaborate with various communities (e.g. urban schools, domestic violence shelters, etc) to improve the lives of its residents. First, Goodman et al. identify the importance of examining the assumptions and values that we hold as psychologists, as well as an understanding of how power dynamics effect interactions with clients and communities. Liu and Pope-Davis (2005) posit that power should be conceptualized as a network and individuals are constantly negotiating power and privilege. Individuals need to recognize the ways in which they have privilege and benefits and how they may also perpetuate oppression in their life. Moreover, Prilleltensky and Nelson (2002) described how power can operate under a guise of neutrality, in which psychologists often profess to be value neutral and objective. However, it is the lack of understanding of one's power that can lead to subtle coercion which in turn leads to the blocking of opportunities for one group of people while promoting the well-being of another. Therefore, the second principle described by Goodman and colleagues is the importance of sharing power. The basic idea behind shared power in the context of psychological practice is that both parties (psychologists and communities in need) contribute to community development or improvement in order to resolve problems in the context of a mutual relationship (Goodman, et al., 2004). In this context, psychologists are seen as "co-learners" rather than experts (Goodman et al.).

Third, Goodman et al., 2004 discuss the importance of "giving voice" or maybe more accurately amplifying the voices of the oppressed. In this amplification, it is also important that voice is understood within the context of power relationships that construct race, gender, and social class (Davis, 1994; Lykes, 1994). That is, in listening and "giving" voice, it is always important to reflect and incorporate the culture and context from which the person has developed his/her identity and worldview. Goodman et al., (2004) proposed that giving voice can be accomplished by approaching communities as if they themselves have the answers to the problems in their community, but need assistance in implementing effective strategies for dealing with the problems. Although community members may not always be aware of their own strengths and resources in dealing with problems, it is important that psychologists use approaches (e.g. narrative approaches) that elicit stories about ways in which community members solved problems in effort to build upon current strategies and increase community self-efficacy. 
The fourth and fifth principles of a social justice application outlined by Goodman et. al. (2004) are directly related to the concept of "giving voice." They draw from the feminist and multicultural literature to incorporate "consciousness raising and building on strengths" as two important components of social change. Consciousness raising involves helping clients to understand the context in which they live and how larger societal institutions (e.g., history of racism, oppressive policies) may contribute to their individual difficulties or community oppression. Lastly, Goodman et al. (2004) write "the aim of our collaboration is not to develop a one-sided or hierarchical dependency that may render community or system helpless once we leave, but rather to support strengths that will continue to thrive beyond our explicit involvement. (p. 807)." In other words, it is important that psychologists "leave clients with tools" so that community partners are assured of continued growth and empowerment long beyond psychologist involvement.

\section{Social Justice and Training}

The theories and ideas outlined in the previous section provide a framework in which to help students understand the theoretical and practical underpinnings of a social justice agenda. And while social justice and advocacy are important in theory, faculty and trainers often struggle with the practical implementation of social justice in their own work, as well as in providing "hands on" training experiences for students. Additionally, the incorporation of new social justice ideas challenges existing training notions and agendas. Resistance may arise from (a) the frustration by many faculty members not knowing how social justice and advocacy can be accomplished without increasing their current curricular loads, and (b) not knowing how to address power within their academic setting (Liu \& Pope-Davis, 2005). Therefore, it is equally important to address some of the ways in which faculty can work within the larger academic infrastructure to provide students with practical exposure to the practice of social justice Next, we discuss two ways that this may be accomplished within applied psychology programs.

\section{Social Justice Training Avenues}

Service Learning. One practical way faculty members have been accomplishing the goal of including social justice into the curriculum is through use of Service Learning. The University of Iowa Center for Teaching (2005) defines service learning in the following way:

"Service learning is defined as a teaching method that connects academic coursework to community needs and concerns. Service learning is a deliberate, adaptable, interdisciplinary pedagogy based on civic education, lifelong learning, and intellectual rigor which seeks to deepen students' understanding of course content and builds on students' existing interest in public service by providing opportunities to learn through experience....Service-learning courses enable students to inform and expand upon their classroom learning by addressing community needs and concerns, understand and reflect on their community-based experience in the context of their academic training, learn about the structure and purposes of community-based and public organizations, and understand and appreciate their own roles as members of a civic community and as citizens of a democracy."

The goals of service learning are very consistent with a social justice perspective and in many ways serve to introduce students to both theory and research, as well as concrete ways to get more involved with the larger community that is home to that university. Many of the goals of service learning are consistent with a critical psychology and social justice agenda. For example, 
social justice perspectives stress the need for psychologists to extend their understanding of individuals and practice to intervene beyond the individual level to larger systemic levels (i.e. local communities or federal government). One of the main goals of service learning is to connect students to their community and actually challenge students to apply theoretical knowledge to helping individuals living within that particular community at any one of the systemic levels. Additionally, the students are asked to continual reflect on their experiences in a way that assists them in understanding the importance of social justice.

There is some evidence to suggest that service learning programs which integrate service and academic learning through continuous reflection promote the development of the knowledge, skills, and cognitive capacities that are essential for students to deal with the complexity of social issues that impact citizens (Eyler, 2002). Additionally, Eyler asserts that the few studies that have been conducted on the impact of service learning on communities indicate that community partners generally value the service offered by students.

\section{Unique Practicum Experiences}

Another way that counseling psychology programs may integrate and provide practical experience with social justice is through the development of unique practicum experiences. For example, the creation of practicum opportunities, which provides services for underserved populations or that focus on public policy initiatives. At present, the extant theoretical and empirical literature has not explored the relationship of social justice and practicum experiences in applied psychology training programs.

Recent scholarship in the area of social justice (e.g. Toporek \& Liu, 2001; Goodman, et al., 2004) has provided excellent theoretical and practical initiatives to assist counseling psychologists in achieving social justice in applied work. In the next section, we attempt to build upon these previous initiatives by discussing two concrete, practical examples of implementing social justice initiatives into the everyday training experiences of our students. These two experiences described in the next section focus on the integration of social justice within the existing components of training and therefore, are a relatively practical way of introducing the impact of poverty, racism, classism, etc. to students. Additionally, they provide a way that students can actively engage in change efforts at a microsystem level.

\section{Practical Examples of Social Justice Training}

\section{Homeless Shelter Practicum}

The homeless shelter is an example of social justice practice at the University of Iowa. The homeless shelter practicum arose from the research interests of a faculty member. The faculty person's research addressed poverty, social class, and classism and his interests in social justice. The homeless shelter opportunity is important to discuss because it illustrates the connection between research and practice within a training program. A faculty member's interest in social justice and homelessness and the ability to provide appropriate supervision are all linked. It would be difficult for a training program to provide this social justice opportunity without the ability to provide the collateral support needed for a practicum (i.e., supervision). The homeless shelter also offers students an opportunity to engage in social action at an individual and community level through direct service to individual clients but also by advocating 
for clients to various agencies. Trainees are also exposed to national and social issues focused on housing and poverty for instance. Therefore, the in-class discussions about poverty, for example, are experienced in-vivo, and supervision helps students understand their reactions. For instance, homelessness is often the intersection of multiple oppressions such as social class and classism, race and racism, and sexism. For many students, this may be the first time they have contended with these multiple intersections, and combined with their own privilege, status, and life experiences, working at the homeless shelter may be overwhelming at first.

\section{Challenges}

Faculty Perspective. From a faculty perspective, the most significant hurdle encountered in establishing the homeless shelter as a practicum site was the university. The university felt that their responsibility was to ensure the safety of the students at the homeless shelter. In discussing the reservations with the university's legal counsel, the challenge was to overcome was the stereotype of homeless individuals as erratic and interpersonally dangerous. Working under this assumption, the legal counsel suggested that counseling be conducted in open settings and disregard confidentiality, students always be provided with staff supervision, and that liability be the responsibility of the homeless shelter. Through various discussions and assurances, the university agreed to have the homeless shelter be regulated as any other practicum site - with a primacy on mental health services and confidentiality of the client.

Student Perspective. For a student the main challenges in completing a practicum at this site are numerous and include lack of a designated psychotherapy room; the non-traditional nature of the site; and redefining psychotherapy to meet the needs of the population served by the shelter. Despite the apparent need for psychological services at the shelter there is no designated space to conduct traditional psychotherapy (face-to-face meeting in a therapy room behind closed doors), or a mental health care provider on staff. Staff member's offices are utilized for psychotherapy sessions when the staff member is not present. There are not set guidelines for scheduling psychotherapy sessions, and it quickly becomes apparent that following the traditional model of psychotherapy (that is, meeting once a week, for a 50 minute session, behind closed doors) does not hold for this setting.

The provision of psychotherapy services may occur in an office space, in the resident's room, out on the porch, or while the resident is preparing her/his meals. The definition of psychotherapy as learned in coursework begs to be redefined in this site. Since it is difficult to guarantee the continuity of psychotherapy sessions due to the length of resident's stay in the shelter, as well as resident's schedule which may change due to an opportunity to work for money; thus it becomes difficult to establish even short-term goals for therapy, as each session is viewed as being the final one. Therefore, psychotherapy at the shelter includes conversing and empathizing with a resident, playing with or reading a story to the children, assisting residents with writing a letter, or searching for a job, providing residents with support and being their advocate as they are being transitioned to other agencies (e.g. long-term residential facilities for individuals with chronic mental illness) or programs (out-patient day programs to cope with chronic mental illness, vocational rehabilitation programs). Maslow's hierarchy of needs (1970) takes precedence at this site, as the residents are struggling to meet their basic needs of food, shelter, and clothing, and thus the focus of psychotherapy is on helping residents find appropriate resources to meet these needs, in addition to providing residents with empathy and support. 
The practicum student at the shelter juggles multiple roles, including psychologist-in-training, case manager, crisis interventionist, assessor and a resource for appropriate sources, while also being a member of the shelter community and participating in the day-to-day activities including helping set-up for and cleaning up after dinner. The non-traditional nature of this site is a challenge for practicum students as they learn to adapt to ambiguity and juggle their multiple roles at the site. This challenge is a strength of the shelter and a rewarding aspect of completing practicum at this site. This site makes one re-think traditional definitions of psychotherapy, and allows one to be more creative in service provision. It also exposes students to a population which experiences great psychological stress and lacks access to health care services and resources. The psychotherapy practicum at the homeless shelter is one practical way of integrating social justice into applied psychology and helps students to understand non-traditional ways of accessing and providing services for under-served populations. Another practical example is incorporating service learning into existing courses such as the career interventions course. The career interventions will be described next.

\section{Career Intervention's Course}

The career interventions course in the University of Iowa's counseling psychology program serves as an introductory course in career development, vocational psychology, and career counseling and interventions. Usually, it is the only course and most of the time the only exposure to career development and counseling that students have in the program. Drawing from the exemplary work of Goodman and colleagues (2004) at Boston College, this course was converted into a service learning course. The faculty believed that this class was compatible with both the goals of service learning and a social justice perspective, as vocational psychology and career counseling was initiated from the work of Frank Parsons, who provided vocational assistance to youth and immigrants in the early 1900's. Many authors (e.g. Blustein, 2006; Petersen \& Gonzalez, 2005) have discussed how the early work of Frank Parsons was the initial roots of social justice in vocational psychology.

Building on this work and the work of others at Boston College, the goals of this course were to: (1) Expose students to social justice perspectives within the career counseling and vocational psychology literature, (2) Expose students to career development/vocational psychology theories and assessment techniques while simultaneously discussing their applicability to promoting a social justice agenda, (3) Provide students with a collaborative experience in which they work with a community agency to participate in a social justice experience that benefited local community agencies and (4) Develop a portfolio of contents related to the work that they completed in the course including reflective summaries of their experience and a report about their activities within the community agency.

Introduction to Social Justice and Vocational Psychology. Before the students had any exposure to the topic of social justice, students were asked to write a brief (1-2 page) reflection paper that outlined their own personal definition of social justice and to speculate on the role of vocational psychologists in this definition. They were asked to put this paper in their portfolio under the heading of "My Initial Social Justice Philosophy."

In the first few weeks of the class (weeks 2-4), students were exposed to the contemporary writings on social justice within counseling psychology and career development. They read the work of many theorists and authors who espoused a social justice perspective, as well read 
some of the controversial issues that surround this perspective. During these first few weeks, students participated in a structured debate that involved debating the pros and cons of social justice work in vocational psychology, as well as the advantages and disadvantages to becoming a social change agent. The students were divided into two groups; both groups took an opposite stance towards training in social justice (either positive or negative). They were given questions and scenarios to debate around the definition of social justice including values, political and moral issues, positions, resources, training perspectives, and the sustainability of social justice initiatives. The goal of the debate was to foster critical thinking about the roles, privileges, values, and feasibility of vocational psychologists engaging in social justice initiatives.

Career Theories and Social Justice. The next few weeks of the course focused on career development theories, namely trait factor theories, developmental theories, social learning theories, and contextual theories. Each of the theories were presented so that students had the opportunity to engage in experiential exercises that helped them to identify how each theory contributes to or can be used from a social justice perspective. These exercises included applying theories to case studies, structured discussions, videos, and guest lecturers. They were exposed to theorists and notable scholars in the field's writings that discuss the integration of a particular theory with a social justice perspective.

Career Counseling (A Different Type of Experience). During the third part of the course, the students had the opportunity to actually take the theoretical and practical knowledge they gained and apply this to an underserved population. Two local community agencies were interested in partnering with the instructor. These agencies were interested in having students assist their clients with job/work related activities. The two agencies were the homeless shelter (described previously) and the STAR program, which is a case management program that provides assistance to individuals in the community who have either transitioned from homelessness to stable housing or meet the poverty threshold for services. The staffs of both of these organizations requested that students meet individually with residents and clients to assist them with basic level job needs including assessing their interests, job search procedures, resume writing, and identifying transportation and overcoming obstacles they see to finding a job. It was agreed that a starting point for this collaboration would be to ask students to spend three hours with residents or clients (one hour a week for three weeks). The staff believed that because of the transitory nature of the residents and clients of homeless shelter and STAR program the best use of the students' time would be able to have them assist clients and residents navigate the initial issues they face when trying to find steady employment.

During the remainder of the course, time was provided for students to discuss their work in the homeless shelter and STAR program, and they openly discussed the challenges, rewards, and frustrations they experienced. For example, students discussed their need to remain flexible and modify the information they have gained to accommodate the needs of this population. They were also introduced to the very real struggle that can ensue when one embarks upon work connected to social justice. For example, they encountered feelings of suspicion and mistrust from the residents of the homeless shelter. They also encountered scheduling issues and frustration with the limited availability of resources for the homeless population.

At the end of the course, students were asked to re-write their social justice philosophy paper with their new experiences in mind. They critically reflected on their initial positions and modified these according to the experiences with either the homeless shelter or STAR program. 
Many of the students discussed the challenges and frustrations they experienced and were able to contrast this to their practicum experiences at the University Counseling Service (students were also simultaneously participating in their first therapy practicum at the University Counseling Service). Both the faculty's and student's perspective on the challenges and opportunities that this experienced provided are detailed in the next section.

\section{Career Practicum Challenges}

Faculty Perspective. There were also some very real and practical challenges to setting up this experience from the faculty perspective. Balancing the academic rigor and service portion of the course was certainly one of the main issues that arose. Time was another factor, as it took considerable time and energy to meet with community organizations to collaboratively design an experience that would fulfill both the student and organizations' needs. There were many instances in which the first author almost decided not to pursue this opportunity because of the time investment which distracted her from other activities that would be more aligned with earning tenure. However, the most pressing issue that the first author faced was the issue of sustainability of the services. This was a one semester class that lasted only 16 weeks. Therefore, there was limited sustainability to this type of service. This remains one major challenge for the next time this course is taught. More attention needs to be paid to the sustainability issues and the actual benefit of the services given the limited amount of time devoted to them.

Student Perspectives. For students, prior to working with the STAR program, the definition of applied social justice in a vocational psychology or a career counseling setting is fairly typical of a trainee at the beginning levels. All individuals have the right to equality, and applied social justice should act as a catalyst for change that would uncover the ways people are oppressed. Vocational psychologists have the tools to provide understanding and services that assist individuals in finding opportunities and support for a better life. In particular, vocational psychologists have the responsibility to provide information and guidance to clients concerning education, career plans, and information about how to navigate the system. Ultimately, most students want their clients to have access to opportunities, recognize their possibilities, and achieve future goals through their interest development and professional support. Although these initial views of social justice in a vocational counseling setting are noble and worthy of consideration, students often realize that the tools they possess and plan on implementing, (i.e. career interventions), are not always immediately appropriate.

It is through the real experiences of implementing social justice interventions that students often reevaluate their views of social justice. For example, the fourth author realized an important component of social justice was self-efficacy, as it impacts an individual's ability to contemplate change. The fourth author recognized many barriers that needed to be considered and addressed. First of all, there were barriers of transportation, errands to be completed, unstable living situations, relationship issues, financial burdens and obligations, and an intimidating job market for those who have a less than optimal work history. Apprehension about an unknown future and limited access to services impacted many of the ideas that were discussed with clients in an open deserted mall. Moreover, many of the individuals were unfamiliar with supportive encouragement and had difficulty feeling efficacious about their aspirations. 
The fourth author reflected on this experience and came to several realizations. First, although support and encouragement were key ingredients in working with clients, it was important to balance the therapist's idealism with the client's real-life situation and context. For clients, it is important to recognize and accept the perceived barriers and to work with clients to find alternative routes to success. One option was to connect clients with community resources and to educate clients on how best to navigate these resources.

\section{Summary and Conclusions}

The focus of this article was to provide examples of clinical training opportunities students may engage in to further develop their orientation toward social justice and to become multi-culturally competent. Two examples such as the homeless shelter and the Career Interventions course illustrate the potential ways social justice can be infused into the doctoral training of counseling psychology students.

As mentioned previously, there have been a few issues related to the implementation of these two programs. Insurance and university liability was one issue faced on the outset of establishing a practicum at the homeless shelter. Within the career counseling class, the instructor faced the issue of trying to balance academic rigor and service learning. This is one of the major issues facing faculty who wish to provide service learning opportunities to their students. Within this type of classroom learning comes the constant challenge of also not giving students the impression that a service learning course is a "blow off" course or is not academically rigorous and intellectually challenging. Another issue is that faculty may want to increase social justice opportunities for students, but fear it would increase their own work load as well as adding to already crowded counseling psychology curriculum. One way to address this is not by increasing the number of courses or hours students must commit in a program, but rather thinking non-traditionally about what doctoral training means and how it is conducted.

An additional issue is broader systemic change. While the two examples discussed provide a foundation in which to train students and expose them to real life examples of implementing social justice ideals, these practical experiences do not fulfill a more radical social justice agenda of changing systems or structures that sustain oppression and inequality. It is important to recognize that a true social justice philosophy would simultaneously train students and provide opportunities to engage in this type of systemic change. Currently, the counseling psychology program at the University of Iowa is engaged in trying to find ways that this can be done by creating sustainable programs and having students become more involved in research that can influence public policy on issues such homelessness, poverty, and education. In addition, students have also created their own social justice initiatives within the program that reach out to the community. While at times it seems daunting to try to integrate good clinical and research training with a social justice agenda, it can be accomplished through the integration and infusion of social justice with existing experiences in which students and faculty are engaged. 
Journal for Social Action in Counseling and Psychology

Volume 1, Number 2 Spring 2008

\section{References}

Blustein, D.L. (2006). The Psychology of Working. Mahwah, NJ Lawrence Erlbaum.

Bullhan, H.A. (2003). Frantz Fanon and the psychology of oppression. New York: Plenum.

Davis, K. (1994). What's in a voice? Methods and metaphors. Feminism \& Psychology 4 (10): $353-61$.

Eyler, J. (2002). Reflection: Linking service to learning-Linking students and communities. Journal of Social Issues, 58, 517-534.

Fouad, N.A., (2006). Multicultural guidelines: Implementation in an urban counseling psychology program. Professional Psychology: Research and Practice, 37, 6-13.

Goodman, L.A., Liang, B., Helms, J. E. Latta, R.E., Sparks, E., \& Weintraub, S.R. Training Counseling Psychologists as Social Justice Agents: Feminist and Multicultural Principles in Action. The Counseling Psychologist, 32, 793-837.

Gross, S.M. (2005). Student perspectives on clinical and counseling psychology practica. Professional Psychology: Research and Practice, 36, 299-306.

Kaslow, N.J., Pate, W.E., \& Thorn, B. (2005). Academic and internship directors' perspectives on practicum experiences: Implications for training. Professional Psychology: Research and Practice, 36, 307-313.

Liu, W.M., \& Pope-Davis, D.B. (2003). Moving from Diversity to Multiculturalism: Exploring Power and the Implications for Psychology. In Pope-Davis, D.B., Coleman, H.L.K., Liu, W.M., \& Toporek, R.L. (Eds.) The handbook of multicultural competencies in counseling and psychology, (pp. 90-102). Thousand Oaks: Sage.

Liu, W.M., \& Toporek, R.L. (2004). Advocacy in Rehabilitation Counseling. In D.R. Maki \& T.F. Rigger (Eds.), Rehabilitation counseling: Profession and practice ( $3^{\text {rd }}$ ed.). (pp. 188198). New York: Spring Publishing Co.

Lykes, B. (1994). Whose meeting at which crossroads? A response to Brown and Gilligan. Feminism \& Psychology 4 (3): 345-49.

Peterson, N. \& Gonzalez, R.C. (2005). The role of work in people's lives: Applied career counseling and vocational psychology. Belmont, CA: Thomson/Brooks Cole.

Prilleltensky, I. \& Nelson, G. (2002). Doing psychology critically: Making a difference in diverse setting. New York: Palgrave MacMillan.

Smith, T.B., Constantine, M.G., Dunn, T.W., Dinehart, J.M., \& Montoya, J.A. (2006). Multicultural education in the mental health professions: A meta-analytic review. Journal of Counseling Psychology, 53, 132-145. 
Toporek, R.L., \& Liu, W.M. (2001). Advocacy in Counseling: Addressing issues of race, class, and gender oppression. In D.B. Pope-Davis and H.L.K. Coleman (Eds.), The intersection of race, class, and gender in counseling psychology (pp. 385-416). Thousand Oaks, CA: Sage Publications.

Toporek, R.L., Liu, W.L., \& Pope-Davis, D.B. (2003). Assessing multicultural competence of the training environment: Updated analysis of the psychometric properties of the Multicultural Environment Inventory. In Pope-Davis, D.B., Coleman, H.L.K., Liu, W.M., \& Toporek, R.L. (Eds.) The handbook of multicultural competencies in counseling and psychology. (pp. 183-190). Thousand Oaks: Sage.

Vera, E.M. \& Speight, S.L. (2003). Multicultural competence, social justice and counseling psychology: Expanding our roles. The Counseling Psychologist, 31, 253-272. 